\title{
NARRATIVAS DA DEPENDÊNCIA NAS REDES DE APRENDIZAGEM ONLINE: COMO OS PROFESSORES USAM AS REDES DE APRENDIZAGEM PARA PROMOVER A AUTONOMIA
}

\author{
J. L. MARTINS ${ }^{1 *}$ e B. SILVA ${ }^{2}$ \\ ${ }^{1}$ Universidade Federal do Tocantins. Palmas -TO \\ ${ }^{2}$ Ciências da Educação da Universidade do Minho, Braga - Portugal \\ jlauro@uft.edu.br*
}

Artigo submetido em novembro/2015 e aceito em janeiro/2016

DOI: $10.15628 /$ holos.2016.4002

\section{RESUMO}

Neste artigo analisa-se a instituição de redes de aprendizagens em ambiente virtual e a necessidade de estabelecer a dialogia como estratégia metodológica. Entende-se que a ação dialógica ocorra quando cada sujeito possa agir e/ou construir sua autonomia viabilizando sua construção nas redes de aprendizagem. Para a base empírica deste estudo, analisamos 1327 mensagens de 5 professores em fóruns para orientação do trabalho de conclusão de um curso online com 200 alunos, distribuídos em 5 turmas. Esta pesquisa permite- nos concluir que prevalece o perfil centralizador dos professores, comum na Educação tradicional, mesmo sendo professores experientes em Educação mediada pelas Tecnologias Digitais de Informação e Comunicação (TDIC) e com formação em Educação. O que confirma a necessidade de se investir na formação de professores para a docência online, a fim de superar essa postura tradicional para que a estratégia metodológica colaborativa e interativa das redes de aprendizagem possa ser implementada.

PALAVRAS-CHAVE: Redes de aprendizagem, autonomia, dialogia, fóruns.

\section{NARRATIVES OF DEPENDENCE IN ONLINE LEARNING NETWORKS: THE WAY TEACHERS USE LEARNING NETWORKS SERVICE TO PROMOTE AUTONOMY}

\begin{abstract}
In this article is analyzed the learning network institutions in virtual environment and the need to establish the dialogic as a methodological strategy. It is understood that the dialogic action where each individual can act and/or build its autonomy enables with the construction of learning networks. For the empirical basis of this study we analyzed 1327 posts of 5 teachers in forums for research orientation of 5 classes of an online course with 200 students enrolled. This study allows us to conclude
\end{abstract}

that prevails the centralizer profile of teachers, common in traditional education, even when the teachers are already experienced on education mediated by digital technologies and masters education. This confirms the need to invest in training teachers for online teaching, in order to overcome the traditional approach and for the collaborative and interactive methodological strategy of learning networks can be implemented.

KEYWORDS: Learning networks, autonomy, dialogic, forums. 


\section{INTRODUÇÃO}

A discussão sobre o uso das redes no processo educativo ganhou espaço na última década com a possibilidade da universalização de acesso às tecnologias digitais. Porém, temos dois desafios a superar para termos clareza dos conceitos e da efetividade dos resultados desse debate. Por um lado, é preciso entender as redes enquanto suporte na web que permitem que nos conectemos a qualquer distância por meio de dispositivos de comunicação, mas que, embora sejam eficiente como suporte no processo educativo, enquanto tal, não são uma rede de aprendizagem. Por outro lado, são necessárias competências para o uso metodológico adequado para compor a rede de efetividade educativa.

Este artigo é resultado de uma investigação de literatura que visa esclarecer os conceitos de autonomia e dialogia na construção das redes de aprendizagens e da pesquisa empírica, por meio de análise dos conteúdos dos fóruns. Procuramos entender se os procedimentos dos professores, que atuaram como orientadores de pesquisa no Curso de Especialização em Coordenação Pedagógica oferecido pela Universidade Federal do Tocantins promoviam a autonomia por meio das suas narrativas. Todos os professores orientadores são mestres em Educação com experiência prévia em educação online.

As redes de aprendizagens traduzem uma referência de aprendizagem autônoma e de inovação ao processo educativo, não mais centralizado no professor, em que aprendente/aprendência tornam-se parte de uma rede de informação e formação colaborativa. Porém, usar intensivamente as Tecnologias Digitais de Informação e Comunicação (TDIC) não é suficiente para considerar inovador o processo educativo. Não são estranhas as tentativas de formação de redes de aprendizagens que mantêm o modelo tradicional da educação centrado no professor (MEC/SEF, 1997, p. 31), porém, as redes de aprendizagens colaborativas online são processos que compreendem uma forma interativa de comunicar,, trazendo mudanças na concepção de aprendizagem e do processo educativo (SILVA, 2008 ; DIAS, 2013; LÉVY, 2001; SILVA, 2009).

O sentido da aprendizagem em rede está presente na célebre afirmação de Paulo Freire (1987, p. 36): “Ninguém educa ninguém. Ninguém educa a si mesmo, os Homens se educam entre si, mediatizados pelo mundo". É bom lembrar que as redes de aprendizagem sempre existiram, seja no processo educativo familiar ou na comunidade. Portanto, não são uma criação das TDIC, embora se considere que na educação formal tradicional o sentido de rede de aprendizagem seja pouco explorado. Segundo Silva (2009, p. 95), "Uma pedagogia baseada nessa disposição à coautoria, à interatividade, requer a morte do docente narcisicamente investido de poder". A metáfora da rede identifica a nova realidade que as TDIC proporcionam com a destituição do binômio centro e periferia que caracteriza a relação professor/aluno na educação tradicional. Portanto, encaminhar o processo educativo para a valorização do diálogo pedagógico e constituição de redes de aprendizagem é um importante desafio para superar os modelos pedagógicos centralizados no professor ou em redes hierarquizadas que não permitem que as informações e as interações fluam em todos os circuitos da comunicação educacional.

Uma construção relacional com um centro definido tem a dificuldade de modificação porque a tendência é encerrar-se em sim mesma. No entanto, se estabelecermos uma estrutura comunicacional pedagógica baseada em uma relação rizomática, a tendência é a abertura 
permanente, uma vez que todo rizoma aponta para fora, embora siga em uma direção. Numa situação de aprendência, qualquer texto pode transformar-se em rizoma na medida em que se usa o hipertexto para completar o sentido que se quer dar a informação. Ao mesmo tempo em que não há mais um centro, todos os "nós" tornam-se o centro semântico. Os rizomas comunicacionais entrelaçam e formam as redes em que cada nó é um centro (SILVA, 2009).

Outro aspecto é que as redes de aprendizagem online precisam de um diferencial em relação às demais redes. Se propusermos uma rede com a finalidade da produção de conhecimento como objetivo comum, é preciso organizar os estudos, facilitar o acesso à informação, concentrar nas informações principais, diminuir o tempo gasto com as inúmeras possibilidades de acessos à informação propiciados pela rede. Nesse caso, o professor pode ter esse papel de orientador da rede de aprendizagem. Contudo, é vantajoso que a rede tenha vários animadores para que não haja um esfriamento das ações e que o professor não exerça, necessariamente, o papel de liderança principal, ainda que ele seja a referência do grupo e que venha a contribuir decisivamente para o sucesso na gestão da aprendizagem. De acordo com Marco Silva (Idem, p. 100), "Os professores poderão lançar mão de suas potencialidades para abrir novos espaços de participação coletiva, colaborativa e aí educar, formar". Nesse caso, o professor (que pode ser chamado de tutor ou de orientador) exerce um papel "periférico" na dinâmica da rede porque, o "centro" está em cada participante interessado na aprendizagem. É a docência que tem o papel de estruturar e dinamizar a rede e não apenas estabelecer uma rota (Idem). Nas redes, as rotas são dinâmicas e podem ser resultado dos estilos de aprendizagem dos alunos e das características da própria rede.

O que os alunos encontram numa rede de aprendizagem online é bem mais que o acesso facilitado à informação a partir de terminais de computadores pessoais (DIAS, 2013). O próprio acesso a web, com tantas informações à disposição e quase sempre sem restrição,, permite novas experiências impossíveis pelas formas tradicionais de distribuição da informação educativa. $O$ próprio instrumento de acesso à internet (como o computador, o tablet e o smartfone), a internet enquanto rede global, os serviços de informações e/ou entretenimento, acesso aos mais diversos bens culturais, tudo pode contribuir para experiências mais expressivas que o acesso exclusivo aos livros escolares e aos professores. Segundo Pierre Lévy, os estímulos da rede digital conectam a inteligência solitária de cada aluno ao ciberespaço. Passa a compor uma inteligência solidária ilimitada construída anônima e coletivamente. Diz o autor que a inteligência coletiva "é uma inteligência distribuída por toda parte, incessantemente valorizada, coordenada em tempo real, que resulta em uma mobilização efetiva de competências" (LÉVY, 2000, p. 28). Ainda acrescenta que a inteligência coletiva fundamenta-se no "reconhecimento e enriquecimento mútuos das pessoas" (Idem, p. 29), partindo de um axioma relativamente simples: "ninguém sabe tudo, todos sabem alguma coisa, todo saber está na humanidade" (Idem, p. 29).

Pensar a aprendizagem em rede é pensar as conexões e os nós dessa rede e, para isso, entendemos que o conexionismo contribui para a compreensão de como se constitui esse processo. Segundo González (2010), essa teoria reúne aspetos de neurociência, ciência cognitiva, teoria de redes, teoria do caos, sistemas adaptativos complexos, entre outros. Aliás, para o conexionismo, uma rede de conhecimentos consiste na capacidade de construir e navegar nessas redes, pois o conhecimento e a aprendizagem estão distribuídos numa pluralidade de conexões (DOWNES, 2012). Embora as redes de aprendizagem não dependam das tecnologias digitais para sua existência, como já foi dito, a conexão às redes virtuais na web constitui um instrumento 
importante pela possibilidade de aumentar exponencialmente as conexões às fontes de informações potencialmente úteis e até necessárias para a produção de conhecimento. Como disse George Siemens, "Quanto melhor a qualidade da rede e conexões, melhor será o resultado da troca de conhecimento. Trabalhar na formação de redes eficazes é um desafio importante, tanto como é a utilização de redes para as nossas necessidades cognitivas" (SIEMENS, 2010, p. 21).

Para o conexionismo, a aprendizagem é um processo de criação de redes (GONZÁLEZ, 2010, p. XII) no qual o aluno não utiliza exclusivamente conhecimentos próprios, mas os conhecimentos que estão na rede da qual ele participa e, portanto, quanto melhor for a rede e a qualidade das conexões, melhor será o resultado do intercâmbio de conhecimento. Tradicionalmente, o conhecimento era tratado como estrutura hierarquizada e estática, porém, do ponto de vista conexionista, as redes de conhecimentos são dinâmicas e ecologicamente sensíveis à adaptação constante que se ajusta a qualquer mudança contextual. Notemos que Pierre Lévy subverte esse ponto de vista com o conceito de "ecologia cognitiva" para expressar a dinâmica da aprendizagem adaptativa. Segundo o autor, "Não sou "eu" que sou inteligente, mas "eu" com o grupo humano do qual sou membro, com minha língua, com toda uma herança de métodos e tecnologias intelectuais" (LÉVY, 1993, p. 83).

Com base nas reflexões de Lévy, Downes e Siemens podemos afirmar que o conhecimento é mais extenso do que individualmente podemos conhecer e que as relações ou conexões entre os nós são tão importantes quanto os conteúdos de cada nó. Ao explorar o conceito de inteligência coletiva Pierre Lévy esclarece que essa forma de conhecimento não está apenas nas "cabeças", mas presente em rede. Para o autor, "a inteligência coletiva não é um conceito exclusivamente cognitivo. A inteligência deve ser compreendida aqui como na expressão "trabalhar em comum acordo" (LÉVY, 2000, p. 26), quer dizer, trabalhar em conjunto (inter legere), como ponto de união não só de ideias, mas sim de pessoas, construindo a sociedade.

Consideramos que a gestão da aprendizagem está intrinsecamente ligada a uma educação dialógica, na forma como o conceito foi utilizado por Freire, para explicar e defender a necessidade de haver um processo comunicativo intenso e de 'mão dupla' no processo educativo (SARTORI e ROESLER, 2006). Para Paulo Freire, a formação dos sujeitos na sociedade não é dialógica porque não é estruturada, sendo a dialogicidade um aspecto da racionalidade presente na comunicação educativa. Portanto, a dialogicidade que qualifica a gestão da aprendizagem deve ser objeto também da aprendizagem docente. Nesse sentido, não há distinção entre conteúdos e tecnologias que propiciam ou não a dialogicidade, mas a postura pedagógica assumida pelo educador. Assim, aprendência em rede pode ser mais eficiente para a construção da autonomia na medida em que a participação colaborativa dos sujeitos seja condição para a rede de aprendizagem. Deve ser apropriada como fator constitutivo de cidadania e não apenas como uma questão pedagógica para a mediação em ambiente virtual de aprendizagem.

Paulo Freire $(1975$, p. 33) considera que as estratégias dialógicas na gestão da aprendizagem requerem um tempo que é renegado pela gestão formalista do ensino. Em nome de um tempo que não se pode perder para dar conta do programa de ensino, perde-se tempo com um verbalismo, cuja alternativa é a memorização. $O$ autor afirma que "O papel do educador não é o de "encher" o educando de "conhecimento", de ordem técnica ou não, mas de proporcionar, através da relação dialógica educador-educando, educando-educador, a organização de um pensamento carreto em ambos." O que Freire chamou de método dialógico supõe ao aluno possibilitar situações em que os juízos são necessários para trabalhar tanto a cognição, quanto a 
afetividade e os valores. Essa forma exige do professor maior capacidade de diálogo e criatividade, uma vez que se trata de uma estratégia bem mais complexa que leituras de textos de livros didáticos. Consideramos que assim se potencializa o fazer docente e o educador, "De mero retransmissor de saberes se torna formulador de problemas, provocando, coordenando equipes, sistematizando experiências, a memória da instituição ao longo da vida, tornando possível o diálogo entre as gerações" (BARBERO, 1996, s\p).

O modo tradicional de organização escolar reforça a heteronomia ao desconsiderar que o trabalho docente acontece com sujeitos e que, ao tratá-lo apenas como parte de uma "turma", rejeita a individualidade e dificulta a construção da autonomia. A construção da autonomia está implícita na ideia de uma ação dialógica em um processo educativo horizontalizado e cíclico, jamais verticalizado e linear.

O que se espera da docência dialógica é uma relação de mediador comprometido, mais com a cidadania do sujeito aluno do que com o seu status institucional ou social. Situa-se como ponte entre o saber em potencial e o já conhecido dos alunos por meio do diálogo transformador.

Transpondo os conceitos apresentados para um curso online, podemos afirmar que a tecnologia, além de não ser impeditiva para a dialogia, pode facilitar a docência do professor. Contudo, depende da conjugação da metodologia empregada pelo professor e da sua capacidade de persuasão para o debate. Em geral, todos os ambientes virtuais de aprendizagem disponibilizam interfaces de comunicação e interação. O fórum é um dos recursos mais utilizados pela possibilidade de flexibilizar espaço-tempo necessários para a dialogia no ambiente de aprendizagem online. Todavia, é o professor que fomenta o debate, a tecnologia não promove discussões. O professor pode utilizá-la apenas para enviar mensagens aos alunos, ou promover debates em que cada tópico de discussão virtual seja moderado por um grupo de trabalho, como se faz nos grupos de apresentação presencial. As formas de diálogo podem pautar-se pelo modelo um-um, em que cada aluno pergunta ao professor e o professor responde individualmente, ou pode promover o debate na forma todos-todos em que o professor (ou outrem, podendo ser os alunos), modera e anima a discussão. Consideramos que este modelo último seja o mais adequado para promover uma rede de aprendizagem significativa, na medida em que se baseia na dialogia e na construção da autonomia na gestão da aprendizagem (HARASIM, TELES, et al., 2005).

A instituição de uma rede de aprendizagem em ambiente online pressupõe uma ação dialógica em que cada sujeito possa agir e/ou construir sua autonomia. Por esse motivo, é necessário que a formação docente ajude os professores a se apropriarem das competências tecnológicas, pedagógicas e comunicativas, a fim de lhes dar liberdade (em sentido freireano) para construir o conhecimento e que jamais as TDIC sejam entendidas como ferramentas que dificultam a prática pedagógica. Nesses termos, entendemos que a autonomia resultante de um processo dialógico nas redes de aprendizagem online precisa ir além da concessão do professor para que os alunos hajam de certa forma.

No contexto dos trabalhos de doutoramento que efetuámos, no âmbito de uma vasta revisão de literatura sobre a autonomia, além do trabalho empírico correspondente, entendemos que a autonomia pode ser considerada em três níveis: (i) Autonomia Instrumental, a mais difundida entre os estudiosos da educação e tecnologia devido ao seu potencial transformador das TDIC (COSTA, 2012). Esse é um nível que viabiliza a constituição da rede enquanto recurso para aprendizagem. Nesse caso, a autonomia docente é caracterizada pela capacidade de usar os 
recursos tecnológicos ou metodológicos para promover a gestão da aprendizagem; (ii) Autonomia cognitiva, que é construída nas redes de aprendizagem, facilita o acesso a diversas fontes e diversas leituras (opiniões) dos participantes da rede e favorece a dialogia e a proatividade cognitiva. Constitui-se na aprendência que vai além dos conceitos apropriados, possibilitando a construção de argumentos em associação com a vida. A docência, fundada epistemologicamente, é capaz de perceber o vinculo entre os TDIC e a prática pedagógica; (iii) Autonomia crítica, o nível mais profundo da aprendência, entendendo-a como a capacidade de atuação social crítica proporcionada pela aprendência. Paulo Freire nos ajuda a entender este nível da autonomia: "É exatamente esta capacidade de atuar, operar, de transformar a realidade de acordo com as finalidades propostas pelo homem, à qual está associada sua capacidade de refletir, que o faz um ser da práxis" (FREIRE, 1979, p. 08). Nesse caso, não há forma segura de avaliação que possa "medir" a autonomia crítica, considerando que nem mesmo o próprio aluno sabe realmente $o$ quê e o quanto o que aprendeu servirá de base para sua visão de mundo. A docência é caracterizada pelo uso transformador das TDIC nas suas atividades pedagógicas, e o professor precisa conhecer as tecnologias disponíveis e a viabilidade metodológica para fundamentar a sua tomada de decisão (COSTA, 2012, p. 23).

Consideramos que a autonomia deve ser um princípio norteador da aprendência instituído em todas as instâncias do processo pedagógico. Não se espera que os alunos sejam autônomos (FREIRE, 1996, p. 67), mas a autonomia deve ser parte da gestão da aprendizagem enquanto eixo rizomático constituinte da proposta pedagógica. Todas as competências e habilidades previstas em um projeto pedagógico devem ser orientadas para a aprendência, o que parece redundante, mas os vícios de nortear o processo educativo pela gestão do ensino facilmente submete a aprendência às questões administrativas que dificultam e até impedem a gestão da aprendizagem norteada para apropriação da autonomia.

Neste artigo propomo-nos entender se as narrativas dos professores nos fóruns promoviam a autonomia no sentido que acabamos de explorar. Usamos aqui o termo 'narrativa' com significado de "falas" e "interações" mantidas pelos professores nos fóruns do curso, portanto tem alcance mais amplo que meras mensagens individuais. A seguir apresentamos a metodologia e os resultados da análise dos fóruns que ocorreram nas cinco turmas durante os doze meses que durou o Curso de Especialização em Coordenação Pedagógica. Os cinco professores dinamizadores dos fóruns tinham formação em nível de mestrado em educação e com experiência prévia em cursos online.

\section{METODOLOGIA}

Este trabalho é resultante do projeto de doutoramento cujo objetivo foi investigar a gestão da aprendizagem a partir da apropriação da autonomia discente no Curso (online) de Especialização em Coordenação Pedagógica da Universidade Federal do Tocantins. Foi adotada a abordagem metodológica qualitativa, a partir da análise de conteúdos dos fóruns e memoriais do Curso.

O ambiente virtual Moodle foi o sistema de gestão do ensino usado para o Curso e a interface fórum foi o principal dispositivo de comunicação usado pelos professores e alunos. 0 fórum é um dos recursos disponíveis nas plataformas para cursos online que permite a comunicação assíncrona entre os participantes. Pode ser configurado de diversas maneiras, desde 
uma simples discussão do tipo perguntas e respostas até debates com diversos tópicos simultâneos, inclusive com envio de mensagens de texto aos celulares móveis dos participantes cada vez que uma nova mensagem é adicionada ao debate.

Foi analisado um fórum por turma, totalizando 1327 mensagens dos professores que foram codificadas e categorizadas com suporte do software de análise qualitativa Nvivo. Nesses fóruns, contamos com a participação média de $50 \%$ dos alunos e $39,6 \%$ de mensagens dos professores. Para o processo de categorização optamos por uma codificação aberta, conforme definem Strauss e Corbin (2008, p. 103) que a entendem como "processo analítico por meio do qual os conceitos são identificados, suas propriedades e suas dimensões são descobertas nos dados". Esse processo deu-se em uma etapa exploratória com organização de dados, decorrido da identificação das unidades de análise por meio da leitura sistemática (codificação) e organizada em categorias (categorização). As categorias identificadas foram:

- Autonomia: Indício de que o professor reconhecesse a condução autônoma do aluno ou que o motivasse para a autonomia;

- Proatividade: Indício de que o professor sugerisse ou esperasse que o aluno executasse uma ação, mas que não fosse uma ordem objetivamente;

- Reflexão: Indício de que o professor fizesse questionamentos com o intuito de orientar os alunos, mas que não houvesse ordem ou indicativo de dependência dos alunos ao professor;

- Ordem: Mensagens imperativas sugestivas de que o professor dissesse objetivamente o que deveria ser feito;

- Dependência: Indicativo de que os alunos dependessem das ordens do professor ou que o professor esperasse a dependência.

\section{ANÁLISE E DISCUSSÃO DOS RESULTADOS}

\subsection{Participação nos fóruns}

Ao entendermos os fóruns nos ambientes virtuais como um espaço importante para a comunicação dialógica, e não apenas um local de esclarecimento de dúvidas, é de se considerar também a forma como os argumentos são construídos para que a discussão não fique polarizada no professor e que os participantes (alunos), se não todos, pelo menos a maioria, participem do debate. As categorias que emergiram por meio da codificação deram-nos a condição de perceber a dialogia nas narrativas dos fóruns.

Tabela 1: Participação nos fóruns

\begin{tabular}{|l|c|c|c|c|c|}
\hline \multicolumn{1}{|c|}{ Turmas => } & T1 & T2 & T3 & T4 & T5 \\
\hline Total de mensagens dos professores & 56 & 224 & 243 & 142 & 661 \\
\hline Percentual de participação dos alunos & 67,5 & 19 & 20 & 27 & 7 \\
\hline Percentual de mensagens dos professores & 31 & 47,2 & 34,8 & 37,9 & 65,6 \\
\hline
\end{tabular}

Observamos na tabela 1 que, em média, apenas $50 \%$ dos alunos participaram nos debates, sendo um percentual baixo pelo fato do fórum ser um recurso usado para a orientação da pesquisa que todos estavam realizando. Contudo, os percentuais de participação indicam que no fórum da turma 1 (T1) houve menos mensagens do professor (56) e maior participação dos alunos (67,5\%). No fórum da turma 5 (T5), pelo contrário, ocorreram menos alunos participantes (7\%) e mais 
mensagens do professor (661). Estes resultados permitem perceber que a quantidade de mensagens do professor não é necessariamente o indicativo de que havia um bom diálogo no fórum. Além disso, temos que considerar que a distribuição das mensagens deve ser a mais equitativa possível, na medida em que os participantes se sintam impelidos a participar. Nos fóruns analisados a média foi de 39,6\% de mensagens dos professores em uma média de 20 participantes por fórum, o que também indica forte concentração de mensagens do professor.

O papel acadêmico desempenhado na orientação pedagógica por cada um dos cinco professores foi idêntico, embora atuassem em turmas diferentes durante o período do curso. Porém, a quantidade de mensagens e o enfoque das narrativas dependia da forma como cada um procedia no acompanhamento do fórum. Já observamos, na tabela 1, a clara a diferença entre o total de mensagens do professor da turma 1 (56 mensagens) e o da turma 5 (661 mensagens) e o respectivo percentual de participação dos alunos de (67\%, na T1 e 7\% na T5). As figuras 1 e 2, obtidas por meio do software de análise sociométrica Ucinet, tornam mais clara essa diferença, ratificando que não é a quantidade de mensagens dos professores o fator determinante para a maior participação dos alunos.

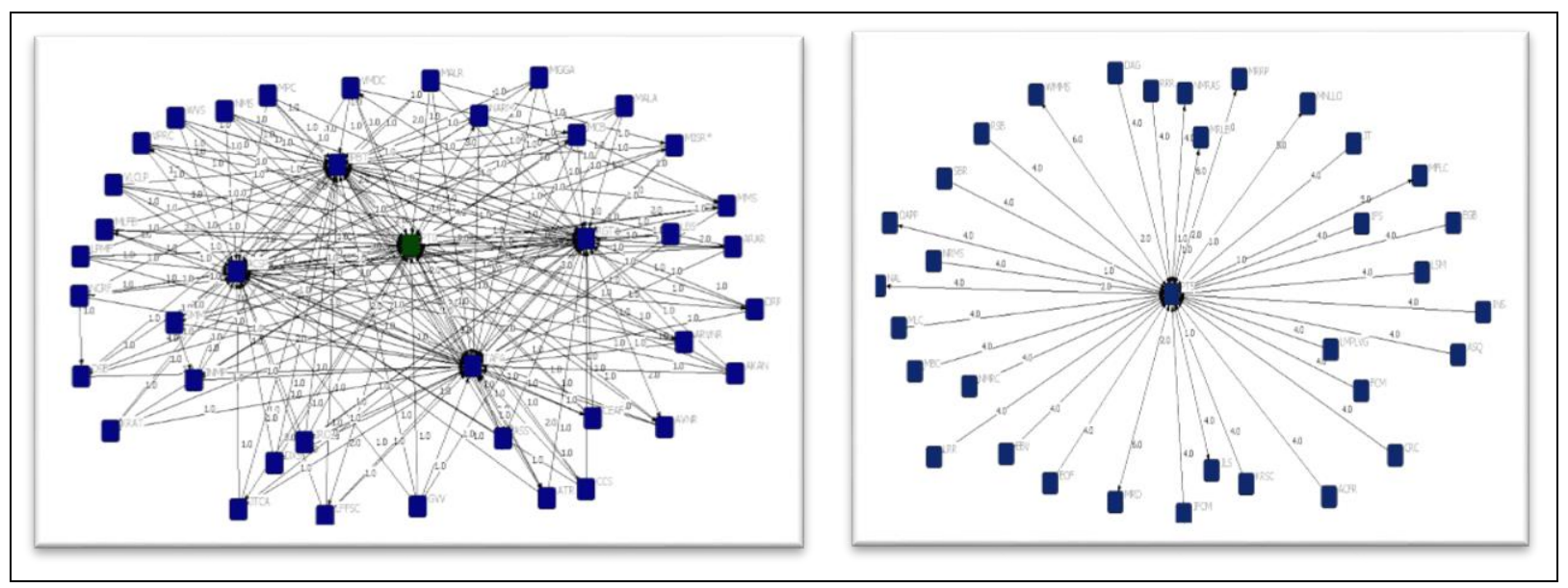

Figuras 1 e 2 - Redes de comunicação (figura 1 - Turma 1; figura 2, turma 5

Durante a codificação para a formação das categorias observou-se também uma relação inversa no total de mensagens codificadas, ou seja, o professor que teve menos mensagens no fórum teve, proporcionalmente, mais mensagens codificadas que o professor que mais enviou mensagens. Indicativo de que a qualidade das narrativas tenha sido um fator importante para a participação dos alunos. Por exemplo, no fórum da turma 5 o professor repetia as informações, chegando a repetir a cada participante separadamente, principalmente quando configuravam ordens em relação às etapas da pesquisa. Com o intuito de ter a certeza de que cada um deles obtivesse a mesma informação, com a repetição de muitas mensagens tornou a narrativa truncada, o que pode ter contribuído para inibir a participação dos alunos e centralizar o debate nele mesmo (o professor). Pois, como considera Silva (1998), se o fator comunicacional da redundância pode facilitar ao "estabelecimento do valor optimum de inteligibilidade de uma mensagem para ser percebida pelos alunos", por outro lado, se existir saturação (repetição frequente) pode originar "falta de atenção e desmotivação dos alunos" (SILVA, 1998, p. 114). 


\section{ANÁLISE DAS CATEGORIAS DA COMUNICAÇÃO}

A análise das mensagens permitiu identificar cinco categorias: autonomia, proatividade, reflexão, ordem e dependência. A seguir, no gráfico 1 , apresentamos os resultados da categorização com os respectivos percentuais.
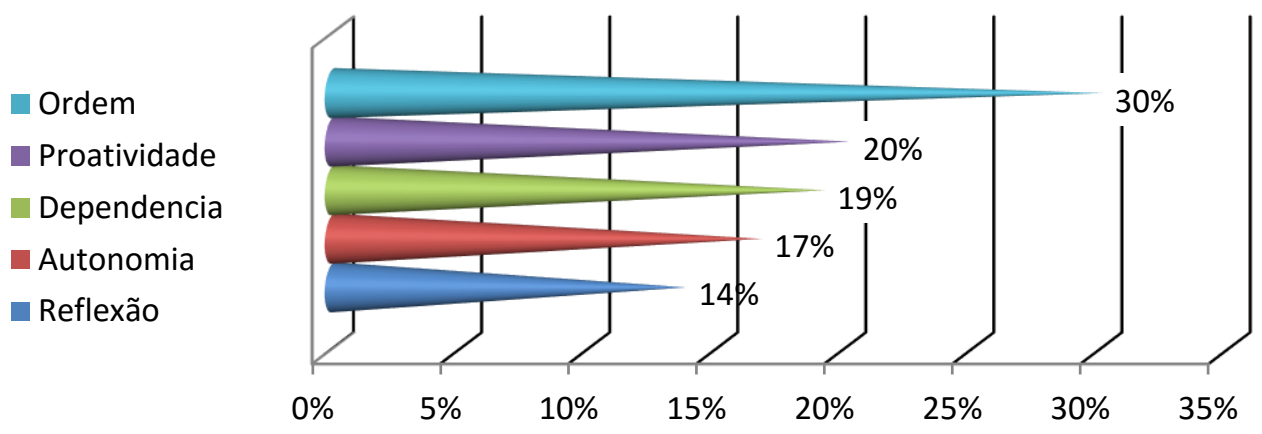

Gráfico 1: Percentuais das categorias

Conforme dados do gráfico 1, comparando as categorias 'autonomia' (17\%) e 'dependência' $(19 \%$,$) , observa-se uma diferença, embora pequena (2\%), porém, em favor da 'dependência'.$ Chamou-nos a atenção a prevalência de mensagens que, objetivamente, tiveram a intenção de determinar o comportamento dos alunos, principalmente com frases imperativas que foram categorizadas por 'ordem' (30\%). Esta constatação é mais evidente se comparamos com as narrativas que não se encerravam em si mesmas e apontavam para a reflexão e a autonomia dos alunos. Nessa comparação, entre as categorias 'ordem' e 'autonomia', a diferença é aumentada para $13 \%$ em favor da categoria 'ordem'.

Se entendermos como neutra a categoria 'reflexão', ou seja, nem autonomia nem dependência, e agruparmos os percentuais das categorias 'autonomia' (17\%) e 'proatividade' (20\%), e os percentuais das categorias 'ordem' (30\%) e 'dependência' (19\%), teremos 49\% das mensagens dos professores que tendem para a dependência dos alunos em relação ao professor e apenas $37 \%$ das mensagens que tendem para a construção da autonomia. Esta análise das narrativas nos fóruns evidencia uma tendência dos professores em manterem a dependência dos alunos no ambiente de aprendizagem online.

Lembrando que na categoria autonomia agrupámos a unidade de análise que os professores reconheciam como autonomia ou que identificavam como motivação do aluno à autonomia, apresentamos a seguir algumas dessas unidades que foram classificadas na categoria autonomia.

Colocando lenha na fogueira: afinal, estas formações são continuadas? Quem acompanha a dinâmica após as formações? Que espaços existem ou podem ser criados para os movimentos de ação-reflexão-ação? Isso não vem sendo por quais motivos? Quais os impasses? (Professor da turma 1)

Sua opção de tema deve refletir a realidade e as vivências locais, bem como a condução de todo o processo didático-pedagógico na escola em que trabalha. $O$ planejamento do ensino é fundamental para o desenvolvimento da aprendizagem, portanto se a questão do planejamento é um problema em sua escola, é uma excelente proposta. Mãos a obra! (Professor da turma 3) 
Com relação às ações que você desenvolveu aqui em Palmas, você acredita que tem possibilidade de refletir e fazer algumas conclusões?? Ou quem sabe a $\mathrm{R}$. poderia te passar as ações (puras, sem nenhuma análise) e você analisar a partir do que você leu?? Vá pensando, enquanto falo com R.. Mas você não tem muito tempo não!! Novembro o relatório deve estar pronto. (Professor da turma 5)

Observamos no gráfico 1 a predominância de mensagens na categoria "ordem" em relação às demais categorias. Isso nos remete ao modelo tradicional de ensino em que o professor é o centro e dá as ordens que os alunos devem seguir. Foram $50 \%$ das unidades de análise com narrativas que indicavam que os seus destinatários (os alunos) realizassem certas ações em dependência das orientações do professor e/ou simplesmente ordens sem margem para qualquer discussão.

Vejamos algumas mensagens que contradizem a postura dialógica esperada nas redes de aprendizagem online. As unidades de análise a seguir exemplificam as ocorrências em que o professor não dá uma ordem objetivamente, porém questiona o fato de suas sugestões não terem sido acatadas:

Li novamente o projeto, e percebi que tem algumas orientações que fiz em janeiro e fevereiro que ainda não foram observadas por vocês, isto vai influenciar no trabalho que terão agora para refazer. (Professor da turma 5)

Não entendi o que ocorreu, vejo que vocês retiram o item conclusão, mas todas as demais correções que fiz e sugeri não foram feitas. (Professor da turma 5)

Ressalta-se a prevalência de discursos imperativos em que os alunos não têm margens para questionamento.

Agora se você não quer mais este tema... então você deve elaborar um novo projeto. (Professor da turma 2)

Volte ao projeto, faça a correção sugerida e traga ele para o encontro presencial que vamos rever. Traga a cópia impressa. (Professor da turma 5)

Veja as orientações e recomendações que fiz na versão que você postou (...). Aguarde informações sobre como fará para apresentar o texto final, se será postado novamente ou se apenas levará impresso para o encontro presencial (...). (Professor da turma 3)

A apropriação da autonomia pressupõe a possibilidade do aluno discordar das orientações do professor, isto pode não ser entendido como exercício da autonomia, embora a discordância faça parte do exercício da construção do senso crítico. Foram encontradas algumas unidades de análise que apresentam indícios de uma situação de "crise" na relação pedagógica. No caso abaixo há uma crítica direta do professor em relação ao que indicou para a correção e o que o aluno realizou. Poderia ter havido uma discordância ou uma atitude relapsa do aluno, contudo não há indício de intenção para entender a razão do aluno para agir daquela forma. Entretanto, sendo a aprendência pautada pela construção da autonomia, até mesmo a atitude relapsa precisa ser considerada como parte da condição autônoma do aluno ou mesmo consequência do exercício de assumir a sua aprendizagem. 
Você não faz ideia do trabalho que é fazer as correções dos trabalhos de vocês. Quando vi que você desconsiderou muitas das correções que fiz na $2^{a}$ versão, fiquei desconcertada. Veja no trabalho que falei sobre isso. $O$ aluno tem liberdade de escrita, afinal o texto é dele, mas quando aponto os problemas é porque não está bom. (Professor da turma 5)

Embora a pesquisa não tivesse como foco as mensagens dos alunos, apenas as dos professores, em alguns casos merecem atenção exatamente pela falta de mensagem para a continuidade do debate ou, até mesmo, as mensagens não permitiam a continuidade da discussão. A mensagem a seguir é exemplo de participação bastante significativa para a orientação dos estudos, contudo não houve continuidade por parte do professor.

Professora, nunca pensei que o tema indisciplina fosse render tanto eu não tinha ideia de sua complexidade. Agora pude perceber a importância dessa temática em sala de aula. Os desafios são constantes. Quando que estou finalizando aparece outro texto mais interessante ainda e tenho novo olhar a cada leitura. $O$ que fazer diante de tantas informações. (Aluno da turma 2)

A seguir, vejamos parte do diálogo extraído do fórum da turma 2 em que o aluno faz uma reflexão sobre a questão do desinteresse pelos estudos dos alunos da zona rural no interior do Estado. Um tema adequado para o fomento de outros alunos na discussão, já que essa turma estava situava em uma das regiões mais remotas do Estado, cerca de $700 \mathrm{~km}$ da Capital. Porém, o professor encerra a discussão com algumas perguntas que distorcem o teor da mensagem do aluno. Ou seja, o problema levantado pelo aluno foi a questão do 'desinteresse' pelos estudos por parte dos alunos da zona rural, o professor, por sua vez, questiona se o trabalho na agricultura é "ruim mesmo".

\begin{abstract}
- Trabalho na educação desde fevereiro de 1986, e durante esse tempo, nunca tinha deparado com alunos desinteressados e sem objetivos de vida, como se percebe nessa geração nova. Para os alunos, aqueles ditos "desinteressados" o que se percebe é que o uso da tecnologia ainda é novidade, até porque faz pouco tempo que passou a funcionar na região. Alguns alunos comentam que não adianta estudar, visto que não conseguem serviço e para conseguir é preciso ir morar em outra região, pois aqui é um município muito carente, em que a maioria dos jovens terminam o ensino médio e não parte em busca de outros caminhos. Acredita-se que muitos adolescentes não apresentam perspectiva de vida profissional por saber que irão continuar desempregados. A realidade é que ao terminar o ensino médio procuram um companheiro (a) casam-se e voltam a trabalhar na agricultura. Observa-se que isso acontece devido a renda familiar que é baixa. Percebe-se que esses problemas são fatores que causam a falta de interesse, de objetivo e de compromisso, por isso pode contribuir com a indisciplina na escola. (Aluno da turma 2)
\end{abstract}

- Vamos continuar a pesquisa... é muito interessante este teu depoimento.... uma pergunta: Por que será que trabalhar na agricultura é tão ruim? Será que é ruim mesmo??? Vamos pensar mais um pouco... Qual é a função da educação? (Professor da turma 2)

Essa postura contradiz ao que se espera quando o objetivo da docência é apoiar a construção da autonomia, uma vez que mantém o professor na postura de autor que, além de 
estabelecer as diretrizes da aprendência, valida os resultados. O discurso docente imperativo enfraquece a autonomia, uma vez que não estimula o aluno a ir além do que é posto pela docência e pelo próprio material de estudos. Não incentiva a escolha, à tomada de decisões, tão pouco estabelece os objetivos e metas de aprendizagem (GUIMARÃES, 2003, p. 23).

A aprendência em ambiente online supõe que todos os atores assumam uma postura dialógica para não se tornar um curso de fato à distância. Ao contrário, a tecnologia permite um 'estar-junto-virtual' (VALENTE, 2003) desde que haja um compromisso com a presencialidade na estruturação do projeto pedagógico. Um dos elementos estratégicos para que a metodologia atenda às necessidades para a construção da autonomia é uma comunicação pedagógica que estabeleça a mediação de forma que o trabalho docente não seja regido por ordens e resistências, mas pelo diálogo pedagógico baseado na reflexão e no questionamento. Para isso, em alguns casos, é preciso mudar a forma de tratamento para permitir e estimular o diálogo. Vejamos a seguir um exemplo.

Muito interessante se o foco for com os professores e juntos buscarem uma saída para as dificuldades das escolas. Tente dar um aspecto de intervenção para reflexões teóricas e práticas efetivas na escola. (Professor da turma 1)

Neste caso, o professor poderia dizer apenas 'o foco deve ser os professores que, juntos, busquem saídas para as dificuldades das escolas'. Não haveria equívoco no conteúdo da ordem, no entanto a dialogia estaria comprometida. Abaixo apresentamos duas mensagens elaboradas por professores de turmas diferentes. Ambas com objetivo de convidar os alunos a participarem do fórum em turmas diferentes.

Este é nosso espaço para orientação sobre a elaboração do projeto de intervenção. Não tenha receio. Vamos conversar e trocar experiências sobre a reelaboração dos projetos. (Professor da turma 1)

Discutam e socializem as dúvidas relativas ao processo de elaboração do II Relatório de execução do PI e elaboração do TCC. (Professor da turma 3)

Percebe-se que um professor faz um convite e nivela-se aos alunos, ou seja, incentiva que os alunos assumam a gestão da aprendizagem, enquanto o outro utiliza da imperatividade para estabelecer uma hierarquia que não inclui os alunos na discussão proposta. A primeira faz um convite ao diálogo, ao passo que a segunda constitui-se em uma ordem, o que contraditoriamente determina que haja o diálogo. É preciso cuidado para que a expectativa de diálogo não frustre os participantes por meio de uma determinação que estabelece o diálogo e não podemos esperar que o diálogo, simplesmente, aconteça porque não é algo natural (FREIRE, 1983).

\section{CONSIDERAÇÕES FINAIS}

A mediação pedagógica para a construção da autonomia exige um professor capaz de construir o diálogo, de manter a sua presença no imaginário do aluno sem que a sua autoridade seja transformada em autoritarismo. Conforme apresentado, nesta pesquisa sobre a aprendizagem em cursos que decorreram no ambiente online prevalece nos fóruns uma narrativa dos professores que evoca a dependência. Entendemos que a construção da autonomia exige, de fato, um diálogo que construa a empatia entre os sujeitos sem a imposição dos discursos 
imperativos, pois, como dizia Paulo Freire, "não cria aquele que impõe, nem aqueles que recebem; ambos se atrofiam e a Educação já não é mais Educação" (FREIRE, 1979, p. 40).

A mediação pedagógica, principalmente em se tratando de curso online, exige mais do que dizer o que os alunos devem fazer. É o acompanhamento por meio do diálogo organizado capaz de instigar uns aos outros a pensarem diferentes. Também é preciso saber identificar os silêncios que compõem o diálogo virtual. Talvez esse seja o maior desafio, pois é relativamente fácil "conversar" com os alunos que estão sempre presentes, porém é difícil não permitir que os silêncios impeçam o sentimento de presença necessário para a mediação dialógica.

Considerando os níveis da autonomia, não foi identificado problema em relação ao nível de autonomia instrumental quanto ao uso dos recursos utilizados para os fóruns, no entanto o alto percentual de mensagens com ordens ou que evocam a dependência dos alunos ao professor identificam certa dificuldade instrumental na construção do diálogo por meios dos recursos utilizados.

Quanto à autonomia conceitual, em tese, todos os professores estavam preparados, considerando que eram mestres em educação e com experiência prévia em educação online. Porém, quanto à autonomia crítica fica evidente que, mesmo tendo o domínio da tecnologia empregada e formação que possibilitasse compreender as necessidades e as possibilidades de uso das TDIC para a dialogia nos fóruns, as narrativas tiveram forte tendência à dependência.

Esta pesquisa nos permite afirmar que prevaleceu o perfil dos professores da educação tradicional, mesmo sendo professores experientes em educação mediada pelas TDIC e mestres em Educação. O que corrobora para a necessidade de se investir na formação de professores para a superação de postura, para que a estratégia metodológica das redes de aprendizagem online possam ser implementadas. Como bem disse Paulo Freire (1987), a dependência gera dependência, portanto quanto mais utilizamos estratégias em que o professor se mantenha indispensável para a aprendência não podemos esperar uma vivência autônoma dos alunos.

A apropriação da autonomia e o uso de uma mediação dialógica permanente exige do professor uma aprendizagem importante para que possa abrir mão do paradigma da centralidade e se posicione como mediador de uma ação em que a aprendência seja o centro do processo e o ensino parte apenas do contexto. No entanto, o que se viu nos fóruns foi que os professores demonstraram ser tradicionais na orientação, com forte tendência às ordens e discursos que pouco ou nada contribuíram para a construção da autonomia.

Finalizamos deixando um questionamento: será que os professores sabem como proceder pedagogicamente para que haja a promoção da autonomia? Levantamos esta questão, com o objetivo de prosseguir com esta pesquisa.

Suspeitamos que os professores utilizam-se do discurso da autonomia, esperando um comportamento submisso dos alunos na realização das atividades indicadas por eles. Isto posto, a autonomia está sendo confundida com a dependência do aluno ao seu mentor e a autonomia é tida como concessão do professor aos alunos de "bom comportamento". Esse é o caminho para futuras pesquisas, entendendo que devemos apostar em pesquisa-formação, uma vez que é possível formar professores para o exercício de uma autonomia cognitiva e crítica em ambiente de aprendizagem online. 


\section{REFERÊNCIAS BIBLIOGRÁFICAS}

1. Barbero, J. M. (1996). Heredando el futuro. Pensar la educación desde la comunicación. Revista Nómadas, № 5, s\p. Disponível em http://www.redalyc.org/articulo.oa?id= 105118998002.

2. Coll, C., \& Monereo, C. (Eds.). (2010). Psicologia da educação virtual: aprender e ensinar com as tecnologias da informação e comunicação. (N. Freitas, Trans.) Porto Alegre, RS: Artmed. (Original publicada em 2008) .

3. Costa, F. A. (Ed.). (2012). Repensar as TIC na educação: o professor como agente transformador. Carnaxide (Portugal), Portugal: Santilhana.

4. Dias, P. (2013). Aprendizagem colaborativa e comunidades de inovação. In M. E. Almeida, P. Dias, \& B. D. Silva (Eds.), Cenários educativos de inovação na sociedade digital (pp. 13-20). São Paulo: Loyola.

5. Downes, S. (2012). Learning Networks. Ottawa, Canadá: National Research Council Canada.

6. Freire, P. (1979). Educação e Mudança (12 ed.). São Paulo: Paz e Terra.

7. Freire, P. (1975). Extensão ou comunicação? Rio de Janeiro: Paz e Terra.

8. Freire, P. (1983). Extensão ou comunicação? (7 ed.). Rio de Janeiro: Paz e Terra.

9. Freire, P. (1996). Pedagogia da autonomia: Saberes necessários à prática educativa. São Paulo: Paz e Terra.

10. Freire, P. (1987). Pedagogia do Oprimido (17 ed.). Rio de Janeiro: Paz e Terra.

11. González, F. S. (2010). La era conectiva: por el desorden natural de los artefactos y nodos. In G. Siemens, Conociendo el conocimiento (D. V. Emilio Quintana, Trans., pp. i-xv). Nodos ele. Disponivel em http://www.nodosele.com/editorial.

12. Guimarães, S. É. (2003). Avaliação do estilo motivacional do professor : adaptação e validação de um instrumento. UNICAMP, Faculdade de educação, Campinas.

13. Harasim, L., Teles, L., Turoff, M., \& Hiltz, S. R. (2005). Redes de aprenizagem: um guia para ensino e aprendizagem on-line. (I. D. Tavares, Trans.) São Paulo: Senac.

14. Levy, P. (2001). A inteligência Coletiva: por uma antropologia do ciberespaço. São Paulo: Loyola.

15. Levy, P. (1993). As Tecnologias da inteligência. São Paulo: Editora 34.

16. MEC/SEF. (1997). Parâmetros curriculares nacionais: Introdução aos parâmetros curriculares nacionais (Vol. 1). Brasília: Brasil/Secretaria de Educação Fundamental.

17. Sartori, A. S., \& Roesler, J. (2006). Narrativa e dialogicidade nas comunidades virtuais de aprendizagem. Revista Compós , 5, (s\p). Disponivel em www.compos.com.br/e-compos.

18. Siemens, G. (2010). Conociendo el conocimiento. (D. V. Emilio Quintana, Trans.) Ediciones Nodos Ele. .

19. Silva, B. D. (2008 b). Tecnologias, Ecologias da Comunicação e Contextos Educacionais. In M. d. Martins, \& M. Pinto (Eds.), Comunicação e Cidadania - Actas do 5o Congresso da Associação Portuguesa de Ciências da Comunicação 2007 (pp. 1908-1920). Braga-PT: Centro de Estudos de Comunicação e Sociedade (Universidade do Minho). 
20. Silva, B. (1998). Educação e Comunicação.

21. Silva, M. (2009). Formação de professores para a docência online. X Congresso Internacional Galego Português de Psicopedagogia, Universidade do Minho, pp. 25-45. Braga, Portugal.

22. Strauss, A., \& Corbin, J. (2008). Pesquisa qualitativa: Tecnicas e procedimentos para a teoria fundamentada (2 ed.). (L. d. Rocha, Trans.) Porto Alegre: Artmed.

23. Valente, J. A. (2003). Educação a distância no ensino superior: soluções e flexibilizações. Interface - Comunicação, saúde e educação , 7 (12), 138-148. 